\title{
Unusual Foreign Body in the Rectum: Case Report
}

\section{Sharief, A Mohamed}

\section{Citation}

M Sharief, A Mohamed. Unusual Foreign Body in the Rectum: Case Report. The Internet Journal of Surgery. 2010 Volume 26 Number 2.

\section{Abstract}

Throughout the history, the variety of objects removed from the rectum almost defies imagination.

We report a case of an unusual foreign body inserted in the rectum as a result of erotic activity in a 23-years-old single male.

\section{INTRODUCTION}

Rectal foreign bodies are large foreign items found in the rectum that can be assumed to have been inserted through the anus, rather than reaching the rectum via the mouth and gastrointestinal tract. We report a case of an unusual foreign body removed bimanually in a 23 -year-old single male patient.

\section{CASE PRESENTATION}

A 23-year-old single male presented with a self-inserted Deodorant Aerosol canister in his rectum. After many attempt of self removal he was presented to the ER department at Riyadh Care Hospital complaining of lower abdominal pain. On examination he looked well both physically and psychologically. Vital signs were normal and abdominal examination showed no signs of localized or generalized peritonitis. A pelvic x-ray film (Fig. 1) showed the object (Deodorant Aerosol canister) (Fig 2) in the rectum above the sacral curve. It was removed bimanually under general anesthesia. The patient was discharged on the second day.

\section{Figure 1}

Figure 1: Pelvic $\mathrm{x}$-ray film showing the object (Deodorant Aerosol canister) in the rectum.

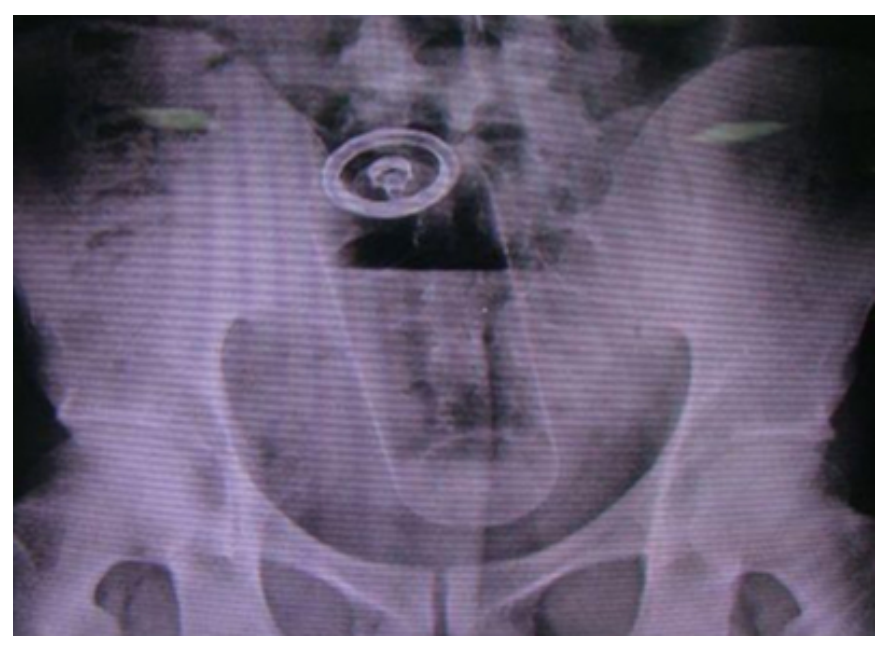




\section{Figure 2}

Figure 2 showing the object (Deodorant Aerosol canister) after removal.

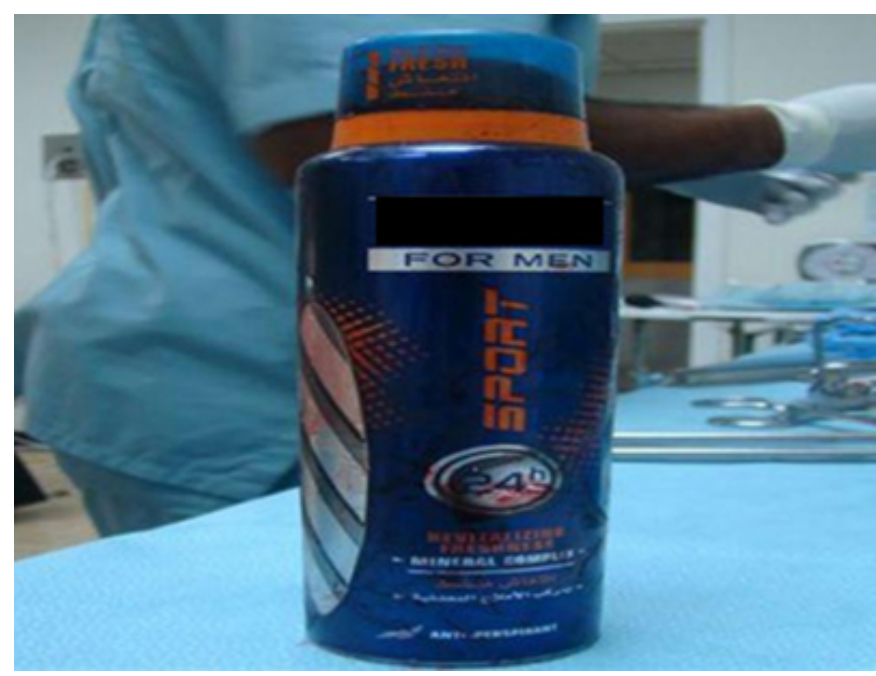

\section{DISCUSSION}

Foreign bodies in the rectum are known for potential complications and present as a challenge to clinical management. The variety of objects removed from the rectum almost defies imagination (1).

The incidence varies according to region, said to be uncommon in Asia and most common in Eastern Europe (2).

Although retained rectal foreign bodies have been reported in patients of all ages, genders, and ethnicities, more than two-thirds of patients with rectal foreign bodies are men in their 30s and 40s, and patients as old as 90 years were also reported (3-5).

Rectal foreign bodies usually are inserted, with the vast majority of cases, as a result of erotic activity. In these cases, the objects are typically dildoes or vibrators, although almost any object can be seen, including light bulbs, candles, shot glasses, and odd or unusually large objects such as soda bottles, beer bottles, or others. Other causes for insertion include diagnostic or therapeutic purposes, self-treatment of anorectal disease, criminal assault and accident (6). Few cases in the literature described foreign bodies in the rectum in association with Munchausen's syndrome $(7,8)$.

Munchausen's syndrome is a term for psychiatric disorders known as factitious disorders wherein those affected feign disease, illness, or psychological trauma in order to draw attention or sympathy to themselves. It is also sometimes known as hospital addiction syndrome or hospital hopper syndrome (8). Assumptions of erotic activity as the cause for insertion of foreign bodies into the rectum may lead to the diagnosis of Munchausen's syndrome being missed.

Some rectal foreign bodies are initially swallowed and then transit through the GI tract. Examples of the latter include toothpicks, popcorn, bones, and sunflower seeds (9). In older men, the objects may be introduced to aid in manual disimpaction for constipation or to massage the prostate.

Rectal foreign bodies present a difficult diagnostic and management dilemma because of delayed presentation, a variety of objects, and a wide spectrum of injuries so that no single procedure for their removal can be recommended. An orderly approach to the diagnosis, management, and postextraction evaluation of the patient with a rectal foreign body is essential (10).

Most patients with rectal foreign bodies present to the emergency room usually after efforts to remove the object at home.

A detailed clinical history and physical examination are essential for the diagnosis and management of these lesions, in addition to any other diagnostic techniques that might be necessary(11).

The first step in the evaluation is that one should always be aware of the possibility of a large bowel perforation and perform radiological investigations. Plain abdominal radiography or water soluble contrast enemas may be helpful. An abdominal X-ray will also provide information on the localization of the foreign body, whether it is below or above the rectosigmoid junction. If perforation of the bowel has occurred, immediate laparotomy is warranted. If there are no signs of perforation, several management approaches can be tried (6).

Rectal foreign bodies can be classified as high-lying or lowlying, depending on their location relative to the rectosigmoid junction. This distinction is important. Objects that are above the sacral curve and rectosigmoid junction are difficult to visualize and remove, and they are often unreachable by rigid proctosigmoidoscope. Soft or low-lying objects having an edge could be grasped and removed safely in the emergency department, but grasping hard objects was potentially traumatic and occasionally resulted in upward migration toward the sigmoid (12).

Frequently, delay in presentation as many patients may be embarrassed and reluctant to seek medical care together with multiple attempts at self-removal lead to mucosal edema and 
muscular spasms, further hindering removal. Rectal lacerations and perforations may occur but are less common than other complications.

A large number of surgical and non-surgical techniques have been described to remove rectal foreign bodies (13).

The approach to remove a foreign object in the rectum depends on the type of object as well as the location within the rectum.

The majority of retained foreign bodies can be removed on an outpatient basis. If removal is not immediately possible, the patient should be admitted for observation and removal of the foreign body transanally under anesthesia (14).

Most objects can be removed either manually or by using different instruments. Historically, various instrument were used to assist transanal removal including use of flexible and rigid sigmoidoscopy (15), colonoscopy (16), obstetric forceps $(17,18,19)$ and obstetric vacuum $(20,21,17)$. Laparoscopic-assisted removal is also described by some authors $(22,23$, and 24).

Laparotomy is only required in impacted foreign bodies and or with perforation peritonitis. Even with laparotomy, the aim is transanal removal and closure of perforation with diversion colostomy. Postretrieval colonoscopy is mandatory to rule out colorectal injury (8).

The complications of insertion of these materials include rectal bleeding, mucosal lacerations, anorectal pain, bowel perforations, abscesses and rarely death (25).

\section{CONCLUSION}

Rectal foreign bodies present a difficult diagnostic and management dilemma because of delayed presentation, a variety of objects, and a wide spectrum of injuries so that no single procedure for their removal can be recommended. Frequently, delay in presentation together with multiple attempts at self-removal lead to mucosal edema and muscular spasms, further hindering removal. Most objects can be removed either manually or by using different instruments. Laparotomy is only required when there is failure of transanal removal as in high or impacted foreign bodies and in presence of evidence of perforation peritonitis.

\section{References}

1. Agarwal P: Long-standing retained foreign body in the rectum. The Internet Journal of Surgery; 2009 Volume 18 Number 2

2. Akhtar MA, Arora PK: Case of unusual foreign body in the rectum. Saudi J Gastroenterol; 2009; 15 (2): 131-2.

3. Ooi BS, Ho YH, Eu KW, et al.: Management of anorectal foreign bodies: a cause of obscure anal pain. Aust N Z J

Surg; 1998; 68: 852.

4. Rodriguez-Hermosa JI, Codina-Cazador A, Ruiz B, et al.: Management of foreign bodies in the rectum. Colorectal Dis; 2007; 9: 543.

5. Clarke DL, Buccimazza I, Anderson FA, et al.: Colorectal foreign bodies. Colorectal Dis; 2005; 7: 98.

6. Koornstra JJ, Weersma RK: Management of rectal foreign bodies: Description of a new technique and clinical practice guidelines. World J Gastroenterol; 2008; 14(27): 4403-4406. 7. Kent JD: Munchausen's syndrome and substance abuse. J Subst Abuse Treat; 1994; 11(3): 247-51.

8. Khan SA, Davey CA, Khan SA, Trigwell PJ, Chintapatla S: Munchausen's syndrome presenting as rectal foreign body insertion: a case report. Cases J; 2008; 1(1): 243.

9. Smith MT, Wong RK: Foreign bodies. Gastrointest

Endosc Clin N Am; 2007; 17(2): 361-82, vii.

10. Goldberg JE, Steele SR: Rectal foreign bodies. Surg Clin North Am; 2010; 90(1): 173-84.

11. Ruiz del Castillo J, Sellés Dechent R, Millán Scheiding M, Zumárraga Navas P, Asencio Arana F: Colorectal trauma caused by foreign bodies introduced during sexual activity: diagnosis and management. Rev Esp Enferm Dig; 2001; 93(10): 631-4.

12. Yaman M; Deitel M; Burul CJ; Shahi B; Hadar B:

Foreign bodies in the rectum. Canadian Journal of Surgery; 1993; 36(2): 173-7.

13. Richter RM, Littman L: Endoscopic extraction of an unusual colonic foreign body. Gastrointest Endosc; 1975; 22: 40 .

14. Barone JE, Yee J, Nealon TF Jr.: Management of foreign bodies and trauma of the rectum. Surg Gynecol Obstet; 1983; 156(4): 453-7.

15. Singaporewalla RM, Tan DE, Tan TK: Use of endoscopic snare to extract a large rectosigmoid foreign body with review of literature. Surg Laparosc Endosc Percutan Tech; 2007; 17(2): 145-8.

16. Rocklin MS, Apelgren KN: Colonoscopic extraction of foreign bodies from above the rectum. Am Surg; 1989; 55(2): 119-23.

17. Mackinnon RP: Removing rectal foreign bodies: is the ventouse gender specific? Med J Aus; 1998; 169: 670-1. 18. Huang WC, Jiang JK, Wang HS: Retained rectal foreign bodies. J Chin Med Assoc; 2003: 66: 607-12.

19. Andrabi SI, Johnson NA, Malik AH, Ahmed M:

Extraction of a rectal foreign body - an alternative method.

Ulus Travma Acil Cerrahi Derg; 2009; 15(4): 403-5.

20. Johnson SO, Hartranft TH: Nonsurgical removal of a rectal foreign body using a vacuum extractor. Report of a case. Dis Colon Rectum; 1996: 39: 935-7.

21. Feigelson S, Maun D, Silverberg D, Menes T: Removal of a large spherical foreign object from the rectum using an obstetric vacuum device: a case report. Am Surg; 2007; 73(3): 304-6.

22. Berghoff KR, Franklin ME Jr.: Laparoscopic-assisted rectal foreign body removal: report of a case. Dis Colon Rectum; 2005; 48(10): 1975-7.

23. Rispoli G, Esposito C, Monachese TD, Armellino M: Removal of a foreign body from the distal colon using a combined laparoscopic and endoanal approach: report of a case. Dis Colon Rectum; 2000; 43(11): 1632-4.

24. Durai R, Biradhar D, Ng PC: Two port laparoscopicassisted removal of a migrating rectal foreign body. Tech Coloproctol; 2010; 14(3): 263-4.

25. Benjamin HB, Klamecki B, Haft JS: Removal of exotic foreign objects from abdominal orifices. Am J Proctol; 1969; 
20: 413-417. 


\section{Author Information}

Mohamed Akram Sharief, MBBch, FRCSed.

Consultant General and Laparoscopic Surgeon, Department of General Surgery, Riyadh Care Hospital

Abbas A. R. Mohamed, MBBS, FRCSI, FICS

Consultant General and Laparoscopic Surgeon, Department of General Surgery, Riyadh Care Hospital 